\title{
An Integrative Workflow to Prioritize Toxicity Initiation Events From Air-liquid-interface Exposure of Human Lung Cells to Combustion Aerosols: First Application to Emissions From a Heavy Fuel Oil or Diesel Fuel Operated Ship Engine
}

\section{Suchi Smita Gupta}

University of Rostock: Universitat Rostock

Jürgen Orasche

Helmholtz Center Munich German Research Center for Environmental Health: Helmholtz Zentrum

Munchen Deutsches Forschungszentrum fur Gesundheit und Umwelt

Thorsten Streibel

University of Rostock: Universitat Rostock

Johannes Passig

University of Rostock: Universitat Rostock

Hendryk Czech

University of Rostock: Universitat Rostock

Jürgen Schnelle-Kreis

University of Rostock: Universitat Rostock

\section{Martin Sklorz}

Helmholtz Zentrum München Deutsches Forschungszentrum für Umwelt und Gesundheit: Helmholtz Zentrum Munchen Deutsches Forschungszentrum fur Gesundheit und Umwelt

Olli Sippula

University of Eastern Finland - Kuopio Campus: Ita-Suomen yliopisto - Kuopion kampus

Jorma Jokiniemi

University of Eastern Finland - Kuopio Campus: Ita-Suomen yliopisto - Kuopion kampus

Maija-Riitta Hirvonen

University of Eastern Finland - Kuopio Campus: Ita-Suomen yliopisto - Kuopion kampus

\section{Gunnar Dittmar}

Luxembourg Institute of Health

\section{Tamara Kanashova}

Max Delbrück Centrum für Molekulare Medizin Berlin Buch: Max-Delbruck-Centrum fur Molekulare Medizin in der Helmholtz-Gemeinschaft 
University of Rostock: Universitat Rostock

\section{Jeroen Buters}

Helmholtz Zentrum München Deutsches Forschungszentrum für Umwelt und Gesundheit: Helmholtz

Zentrum Munchen Deutsches Forschungszentrum fur Gesundheit und Umwelt

\section{Benjamin Stengel}

University of Rostock: Universitat Rostock

\section{Horst Harndorf}

University of Rostock: Universitat Rostock

\section{Marco Dilger}

Karlsruhe Institute of Technology: Karlsruher Institut fur Technologie

\section{Christoph Schlager}

Vitrocell Systems GmbH, 79183 Waldkirch

\section{Karsten Hiller}

Université du Luxembourg Luxembourg Centre for Systems Biomedicine: Universite du Luxembourg Luxembourg Centre for Systems Biomedicine

\section{Sean Sapcariou}

Université du Luxembourg Luxembourg Centre for Systems Biomedicine: Universite du Luxembourg Luxembourg Centre for Systems Biomedicine

\section{Shailendra Gupta}

University of Rostock: Universitat Rostock

\section{Olaf Wolkenhauer ( $\triangle$ Olaf.wolkenhauer@uni-rostock.de )}

University of Rostock: Universitat Rostock https://orcid.org/0000-0001-6105-2937

\section{Ralf Zimmermann}

Helmholtz Center Munich German Research Center for Environmental Health: Helmholtz Zentrum Munchen Deutsches Forschungszentrum fur Gesundheit und Umwelt

\section{Methodology}

Keywords: Integrative workflow, Regulatory networks, Combustion aerosols, Mixture toxicity, air liquid interface cell exposure

Posted Date: January 25th, 2021

DOI: https://doi.org/10.21203/rs.3.rs-152521/v1

License: (c) (1) This work is licensed under a Creative Commons Attribution 4.0 International License. Read Full License 
An integrative workflow to prioritize toxicity initiation events from airliquid-interface exposure of human lung cells to combustion aerosols:

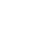

(1)

$27{ }^{9}$ Chair of Piston Machines and Internal Combustion Engines, University Rostock, 18059 Rostock, Germany

$28{ }^{10}$ Institute for Technical Chemistry (ITC), Karlsruhe Institute of Technology, 76344 Eggenstein29 Leopoldshafen, Germany

$30 \quad{ }^{11}$ Forschungs- und Beratungsinstitut Gefahrstoffe GmbH, 79106 Freiburg, Germany

$31 \quad{ }^{12}$ Vitrocell Systems GmbH, 79183 Waldkirch, Germany 
$32{ }^{13}$ Luxembourg Centre for Systems Biomedicine, University of Luxembourg, L-4362 Esch-Belval, 30 33 Luxembourg

$34{ }^{14}$ Chhattisgarh Swami Vivekanand Technical University, Bhilai, Chhattisgarh 491107, India

$35{ }^{15}$ Stellenbosch Institute for Advanced Study (STIAS), Wallenberg Research Centre at Stellenbosch

36 University, 7600 Stellenbosch, South Africa

37

$38{ }^{*}$ Corresponding authors

39 
42 Advancement in the instrumentation techniques made it possible to identify the

43 compositions and concentrations of various chemicals, such as organic compounds or

44 metals in combustion aerosols. However, the prediction of combustion aerosol-induced

45 toxicity end points in lung epithelium cells is difficult due to the large number of non-linear

46 chemical-biological interactions. It is evident that some chemicals present in the

47 combustion aerosols upregulate certain genes/ proteins while other chemicals

48 downregulate them, making the prediction of toxicity of a mixture of chemicals a

49 challenging task. Also, the presence of large numbers of feedback and feedforward

50 regulatory loops makes the entire prediction process highly dynamic.

\section{Methods}

52 Here we present an integrative workflow to construct and analyze combustion aerosol-

53 type specific chemical-gene regulatory network. For this, we develop an algorithm to

54 estimate the combined regulatory effect of chemicals present in the combustion aerosol

55 on each of the genes/proteins in the network. Further we rank the nodes by combining 56 various network topological and non-topological parameters using a multi-objective 57 optimization function. The top ranked nodes were used to identify aerosol-type specific 58 key regulators that contributes toward the understanding of adverse outcomes due to the 59 exposure of combustion aerosols.

\section{Results}

61 The integrative workflow is evaluated using transcriptomics analysis carried out on human

62 bronchial epithelium cell line BEAS-2B exposed at the air liquid interface (ALI) to the 63 combustion aerosols generated by ship engine running either on distillate Diesel Fuel 64 (DF) or on Heavy Fuel Oil (HFO) along with chemometric analysis. Based on the 65 prioritized chemicals, we prepared DF and HFO combustion aerosols-specific chemical- 
66 gene regulatory network. Our study reveals the large differences in the observed

67 biological effects caused by operating the same ship engine on the different fuels.

\section{Conclusion}

69 The presented workflow can be used to investigate key regulatory processes associated

70 with the toxicity outcomes of mixture of chemicals and also for the hazard classification

71 and assessment of various combustion aerosols.

\section{Keywords}

73 Integrative workflow, Regulatory networks, Combustion aerosols, Mixture toxicity, air

74 liquid interface cell exposure 


\section{Background}

In most risk assessment studies, chemical entities are analyzed individually

79 despite the fact that they are rarely present alone in a real life exposure matrix $[1,2]$. It is

80 assumed that the behavior of chemicals in mixture is altogether different than the additive

81 effect of individual compounds [3-5]. Previously designed theoretical models for

82 predicting the toxicity of mixtures of chemicals present in an exposure matrix (e.g.

83 combustion aerosols) are based on 1) concentration addition/ independent actions, when

84 the overall toxicity of the chemicals in a mixture is the sum of the toxicity of individual

85 chemicals; and 2) synergism/ antagonism, when the overall toxicity of chemicals in a

86 mixture is either higher or lower than the simple addition of toxicity caused by the parent

87 compounds [6]. Figure 1 highlights possible behavior and toxicological outcomes of two

88 chemicals when present in an exposure matrix.

While there is increasing evidence that the cellular environment plays a crucial role

90 in toxicity outcomes after exposure [7], advances in the omics technologies provide us

91 with data that can be used to identify and characterize underlying mechanisms related to

92 toxicity initiation events and progression [8-10]. Molecular mechanisms associated with

93 the toxicological outcomes due to the exposure of xenobiotic are highly dynamic in nature,

94 making the risk assessment of chemical mixture a difficult process [11]. It is well

95 established that environmental chemicals can influence the expression profile of

96 regulatory genes $[12,13]$ involved in the mutagenesis. These chemicals also interfere in

97 the physical interactions of the biological molecules and thus play a crucial role as

98 etiological agents to make an organism susceptible for many chronic diseases $[7,14]$.

99 Figure 2 highlights some of the dominant mechanisms associated with carcinogenesis, 
100 cardiovascular and lung diseases due to combustion aerosol exposure. The combustion

101 of fuels generates fine and ultrafine particles as well as reactive gas-phase species which

102 are responsible for the production of reactive oxygen species (ROS), DNA stands breaks

103 and initiation of signaling mechanisms inducing inflammations [15,16].

Combustion aerosol emissions from marine traffic have increasingly gained

105 attention in the past two decades. Ships use large diesel engine without exhaust cleaning

106 devices, that are common for road traffic vehicles and they burn fuel of low quality. In

107 particular, the combustion of heavy fuel oil (HFO), a residue from crude oil vacuum

108 distillation blended with middle distillate, releases substantial amounts of PM, including

109 heavy metals and Black Carbon $(\mathrm{BC})$, as well as $\mathrm{SO}_{x}$ and $\mathrm{NO}_{x}[17,18]$. Epidemiological

110 studies on different spatial scales found that ship traffic is significantly associated with the

111 number of premature deaths and air quality in especially harbor cities $[19,20]$.

112 Consequently, the International Maritime Organization decided to reduce the sulfur

113 content of marine fuel in order to promote low-sulfur, i.e. "cleaner", fuels or the use of

114 sulfur scrubbing technology [21]. However, sulfur scrubbers operated in open-loop mode

115 has been heavily criticized because of severe environmental threats [22-24]. Since 2020,

116 ship owners have to comply with a mandatory global sulfur limit of $0.5 \%$ and $0.1 \%$ in so-

117 called sulfur emission control areas (SECA). SECAs refer to sensitive ecosystems or

118 areas with high population density and comprise Baltic Sea, North Sea, English Channel

119 and most North American coastal waters. Although forecasts and assessments on

120 consequences for human health suggest a beneficial effect from recent sulfur regulations

121 [25-28], ship emissions refer to diesel exhaust without exhaust aftertreatment, for which

122 the toxicity is well-known[29]. In fact, toxicological studies comparing several biological 
123 endpoints and a multi-omics approach in in vitro exposures revealed that even the use of

124 fossil diesel with the lowest sulfur content of available on the market leads to a rather

125 different than lower toxicity[30,31].

126 In the last few years, many sophisticated instrumentation techniques were

127 developed and used to study the overall chemical compositions from combustion aerosols

128 of the marine traffic sector. For example, Rüger et al. used ultra-high-resolution mass

129 spectrometry coupled to laser desorption/ionization for the detailed molecular level

130 analysis of combustion aerosols from ship diesel engine [32]. Mueller et al. analyzed and

131 compared the combustion aerosols generated from ship diesel engine running on heavy

132 fuel oil (HFO) and diesel fuel (DF) using high resolution time-of-flight aerosol mass

133 spectrometry in combination with aethalometer, particle sizer, online gas phase and filter

134 measurement to conclude that average emission factors were higher for HFO than DF

135 [33]. Kleeblatt et al. and Radischat et al. used resonance-enhanced multiphoton ionization

136 time-of-flight mass spectrometry to analyze aromatic and polycyclic aromatic

137 hydrocarbon from ship engine running on different fuel types [34,35]. Czech and

138 colleagues carried on the their work by in-depth comparison of aromatic emission profiles

139 of ships to other emissions arising from on-shore traffic or residential heating using a

140 chemometric approach [36]. Corbin et al. focused on the trace metal content in different

141 size fractions of HFO-PM by aerosol mass spectrometry and inductively-coupled plasma

142 optical emission spectroscopy and revealed that vanadium is enriched in soot particles

143 belonging to the fraction of ultrafine particles with aerodynamic diameters below $100 \mathrm{~nm}$

144 [18]. A comprehensive comparison of PM from HFO and DF combustion was conducted 
145 by Streibel et al. and Sippula et al., serving as physico-chemical data pool for the merging with toxicological findings[17,37].

In order to investigate undesirable biological responses and toxicity endpoints from

148 the aerosols exposure, researchers are now using realistic and comparable state-of-art

149 in vitro experimental conditions (e.g. air-liquid interface) along with multi-omics profiling

$150 \quad[30,38-40]$. However, due to complex chemical compositions of combustion aerosols and 151 highly dynamic interactions between the chemicals and biological molecules in the 152 exposed cells, mechanistic understanding of toxicity initiation mechanisms is a real 153 challenge [41]. In this study, we develop and present an integrative workflow for 154 generating chemical-gene/protein interaction networks very specific to the combustion 155 aerosols generated through a ship engine which runs on 1) Heavy Fuel Oil (HFO); and 2) 156 Diesel Fuel (DF) and provide various steps to analyze these networks for the prediction 157 of critical regulatory mechanisms responsible for the toxicity outcome after the aerosol 158 exposure.

\section{Methods and methodology}

160 The measurements were performed within the HICE project (www.hice-vi.eu) four161 stroke single-cylinder direct-injection diesel engine test bench with a nominal speed of $1621500 \mathrm{rpm}$, maximum power of $80 \mathrm{~kW}$ and a total displacement of $3.18 \mathrm{~L}$, located at 163 Rostock University, see [17] for details. Briefly, the engine was operated either with clean 164 distillate diesel fuel (DF, EN 590) or with Heavy Fuel Oil (HFO). The chemical composition 165 and the aerosol particle properties of the engine emission were thoroughly characterized 166 by off-line and on-line chemical and physical easements approaches. At the same time, 
167 human epithelial lung cell cultures were exposed at the Air-Liquid-Interface (ALI) using as

168 special at site mobile S2 biosafety laboratory and automated ALI-exposure system. The

169 acute cytotoxicity, the multiomics response of the human, and response pathways were

170 determined. This approach was published in great detail [30]. In this work, a new systems

171 biology-based network approach is used to understand the aggregated effect of

172 combustion aerosol by connecting the chemical data of the emissions to their potential

173 biological targets.

174 1. Chemical exhaust aerosol characterization of the HFO- or DF-operated ship 175 diesel engine

176 The aerosol from the exhaust pipe was first taken through a temperature insulated 177 sampling probe to a pre-cyclone to remove coarse particles from the sample, and then 178 diluted in two stages by applying a porous tube - ejector sampling system (Venacontra, 179 DAS, Finland). The pre-cyclone and the sampling lines upstream of the diluters were 180 heated to approximately $300^{\circ} \mathrm{C}$.

181 The primary dilution was carried out using a porous tube diluter where compressed 182 air flowed through a porous tube wall providing a sheath flow which prevented wall losses 183 of vapours and particles. Thereafter, the aerosol was taken into an ejector diluter with a 184 fixed dilution ratio of roughly 3. After this stage the sample stream was divided to several 185 stainless-steel sampling lines and diluted further with ejector diluters (Palas, VKL $10 \mathrm{E}$, 186 Germany) depending on the desired concentration range. The dilution was carried out 187 with clean, dried and particle free compressed air at room temperature. The dilution ratios 188 were calculated based on $\mathrm{CO}_{2}$ measurements in the raw exhaust (AVL, CEB II) and after 
189 dilution (Vaisala, Carbocap GMP343). The final applied dilution ratios were approximately

19040 for the offline filter and gas-phase sampling, when the engine was operated on diesel

191 fuel (DF), and 100 for engine operation with HFO. Online photoionization mass

192 spectrometers for gas phase analysis were sampling directly from the undiluted raw gas.

$193 \mathrm{PM}_{2.5}$ filter samples for off-line analyses were taken with a modified speciation sampler

194 (Rupprecht \& Patashnick 2300, Thermo Scientific, USA), which could sample four filters

195 in parallel at a flow of $10 \mathrm{~L} / \mathrm{min}$. PM samples were collected on quartz fibre filters (QFF,

196 T293, Munktell, Sweden) and PTFE membrane filters (Zefluor $1 \mu \mathrm{m}$, Pall, USA). The QFF

197 were conditioned before sampling by baking at $500^{\circ} \mathrm{C}$ for at least 12 hours. Immediately

198 after sampling the filters were frozen at $-25^{\circ} \mathrm{C}$. Gas phase carbonyls were collected by

199 derivatisation with 2,4-dinitrophenylhydrazine (DNPH) using commercially available

200 cartridges 'ORBO/555' (Sigma Aldrich, USA). Loaded cartridges were sealed immediately

201 after sampling with quick fit caps and stored in a refrigerator. Inorganic elements were

202 determined from PTFE filters using inductively coupled plasma atomic emission

203 spectroscopy. Analysis of elemental and organic carbon (EC/OC) was carried out from

204 QFF filters by a thermo/optical carbon analyzer (Desert Research Institute Model 2001A,

205 NV, USA) coupled to a time-of-flight mass spectrometer (Stefan Kaesdorf, Munich,

206 Germany) using single photon and resonance-enhanced multi-photon ionization (SPI and

207 REMPI, Diab 2015). Targeted analyses of semi- and low-volatile organic species,

208 including $\mathrm{PAH}$ and o-PAH for example, was done using in-situ derivatization and thermal

209 desorption - gas-chromatography - time-of-flight mass spectrometry (IDTD-GC-ToFMS,)

210 [42]. Carbonyls sampled in DNPH cartridges were quantified as carbonyl-hydrazones with

211 GC-MS [43]. Online analyses of organic gaseous engine emissions were carried out by 
212 single-photon ionization mass spectrometry (SPI-MS) and resonance-enhanced

213 multiphoton ionization mass spectrometry [44]. Black carbon (BC) was determined at 880

214 nm using a multi-wavelength aethalometer.

215 2. Air Liquid Exposure of BEAS-2B human lung cells to exhaust aerosol of a HFO216 or DF-operated ship diesel engine and transcriptome analysis

217 Human bronchial epithelium cell cultures were exposed to diluted ship engine

218 emission aerosols operated with HFO or DF. Detailed experimental settings for the

219 exposure of cells and methodology for analysing transcriptomics data is provided in [38].

220 Briefly, confluent layers of human epithelial SV40-immortalised bronchial epithelial lung 221 cells (BEAS-2B, purchased from ATCC, CRL-9609'M; http://www.lgcstandards-

222 atcc.org/Products/All/CRL-9609.aspx) were exposed to diluted (1:40 or 1:100, see (21))

223 engine exhaust for $4 \mathrm{hrs}$ at the air-liquid-interface (ALI). The lung cells have direct contact

224 to inhaled aerosol particles and gases and therefore are used as a model of aerosol

225 inhalation. Cytotoxicity tests were performed to ensure a sub-cytotoxic exposure dose 226 and the transcriptomics profile was analysed, the Omics data is stored in Gene

227 Expression Omnibus (GSE63962). All experiments were performed in triplicate and 228 referenced to clean air exposure.

229 3. Construction of combustion aerosol-type specific chemical-gene regulatory $230 \quad$ networks

231 In the following the construction of combustion aerosol-type specific chemical-gene 232 regulatory network is explained step-by step:

233 Step 1: Construction of chemical-gene interaction networks 
234 The information about chemical-gene/protein interaction was collected from

235 Comprehensive Toxicogenomics Database (CTD) (http://ctdbase.org) [45]; chEMBL

236 (https://www.ebi.ac.uk/chembl) [46]; PubChem (https://pubchem.ncbi.nlm.nih.gov) [47];

237 STITCH (http://stitch.embl.de) [48]; AOP KB (http://aopkb.org); ToxCast from US EPA

238 (https://www.epa.gov/chemical-research/toxicity-forecaster-toxcasttm-data) [49]; and

239 other published literature. Many of these databases were designed based on the

240 information extracted directly from experimental studies or through text mining algorithms.

241 We first generated initial network by connecting targeted gene/proteins to the chemicals

242 using basic expression i.e. "chemical $X$ interacts with gene/protein $Y$ " for majority of the

243 chemicals present in combustion aerosol using in house script.

$244 \quad$ Step 2: Setting up of chemical gene/protein regulatory relationship

245 For the genes/proteins connected to a particular chemical in the initial interaction 246 networks, we retrieved experimentally validated interactions among the connected

247 genes/proteins using STRING (v9.1) [50], BioGRID (v3.4) and HPRD (release 9) [51]

248 databases. These interactions were mapped over the initial networks to make them fully

249 connected chemical gene regulatory networks. Wherever possible, we have manually

250 curated each interaction by converting expression "chemical $\mathrm{X}$ interact with gene/protein

251 Y" to "chemical $\mathrm{X}$ increase/decrease the expression of gene/protein $\mathrm{Y}$ " after careful 252 reading of associated peer-reviewed publications. Database such as CTD, STITCH have

253 hundreds to thousands of ambiguous chemical gene interactions where a chemical is

254 shown to increase the expression of a gene in some studies while in others the expression

255 is decreased after the exposure to the same chemical. For such ambiguous cases in our 256 networks, we manually screened original publications and set the interaction type 
257 (increase expression/decrease expression) which is represented by most of the 258 publications specifically validated the chemical-gene association. Furthermore, we 259 annotated gene/protein nodes present in the networks with HUGO name, HGNC ID, 260 Entrez ID and UniProt ID. Finally we integrated all the information to prepare a 261 knowledgebase (KB) containing annotated chemical-gene regulatory networks in 262 Cytoscape [52] compatible XML files for network visualization and analysis.

\section{Step 3: Identification of priority chemicals for HFO and DF combustion aerosols}

In order to identify combustion aerosol-type specific chemicals, we first calculated concentration $\left(\mu \mathrm{g} / \mathrm{m}^{3}\right)$ of various HFO and DF aerosol components, such as chemical 266 compounds, elemental metals and gases in online/ offline measurements. As the aerosols 267 are composed of hundreds of chemical compounds, metal elements and gases, we 268 choose various concentration cut-off to filter out chemicals for the preparation of aerosol269 type specific regulatory networks. In particular, we used concentration cut-off $1000 \mu \mathrm{g} / \mathrm{m}^{3}$

270 for the inorganic components and $1 \mu \mathrm{g} / \mathrm{m}^{3}$ for the organic components in the gas phase 271 compounds of aerosols. For various organic compound classes and particles, the cut-off 272 was set to 1 and $100 \mu \mathrm{g} / \mathrm{m}^{3}$ respectively. For polycyclic aromatic hydrocarbons, we set 273 the concentration cutoff $0.005 \mu \mathrm{g} / \mathrm{m}^{3}$ due to the availability of high-quality toxicity data.

274 For carbonyl compounds and elements, the concentration cut-off was set to 0.15 and 0.25 $275 \mu \mathrm{g} / \mathrm{m}^{3}$ respectively. Furthermore, we assigned individual chemical component to a 276 particular aerosol only if its concentration is more than one order of magnitude in 277 comparison to another aerosol, if not, the chemical was assigned to both the aerosols. 
Step 4: Generating combustion aerosol-type specific chemical-gene regulatory 279 network

280 For the prioritized chemicals identified in step 3 from HFO and DF combustion 281 aerosols, we selected and merged the respective chemical-gene interaction networks 282 from our knowledgebase (Step 2) using 'Advanced Network Merge' application available

283 in Cytoscape v. 3.7.1. In order to further augmenting regulatory interactions between the 284 newly merged biological counterparts in the combined chemical-gene interaction network, 285 we screened STRING [50], BioGrid [53], DIP [54], BIND [55] and HPRD [51] databases 286 for the experimentally validated interactions.

287 All the steps in the construction of this knowledge-based network are summarized in 288 Figure 3. Mapping of gene expression data onto the regulatory network and Identification of 290 key regulatory genes and network analyses

291 The whole transcriptomics profiles from human bronchial epithelium cell line (BEAS292 2B) exposed to complete and filtered DF and HFO combustion aerosol were analyzed 293 using $\mathrm{R}$ and the Bioconductor packages limma [56]. All the transcripts with log2294 expression fold change $>=1.5$ and $p$-value $<0.05$ were considered significant. The official 295 gene symbols were used to map the log2-expression fold change data on the respective 296 combustion aerosol regulatory network for further analyses. With the aim to identify key 297 regulatory genes in the HFO and DF biological response networks, first we measure the 298 overall impact of chemicals present in the aerosol on the node (gene) and then used 299 various network topological parameters along with the expression fold change of the gene 
300 using a multi-objective optimization function as described in our previous publications 301 [57-60]. The algorithm is summarized below:

302 1. For each chemical component $\mathcal{C}_{i}$ in the aerosol network where $i=1, \ldots, j$, we first 303 count number of nodes $K_{\mathcal{C}_{i}}$ directly connected to it.

3042 2. A scaling factor $\mathcal{S}_{\mathcal{C}_{i}}$ is then calculated of each chemical $\mathcal{C}_{i}$ by assuming that the concentration of a chemical $\mathcal{M}_{\mathcal{C}_{i}}$ is equally distributed in the regulation of directly connected genes.

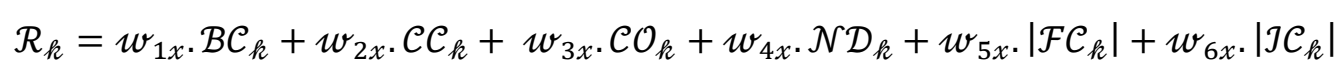
and $x$ is the weighing scenario ( 1 to 7 ) as shown in Table 2. $\mathcal{B C}$ is the betweenness centrality, $\mathcal{C C}$ is the closeness centrality, $\mathcal{C O}$ is the clustering coefficient, $\mathcal{N D}$ is the node degree, $\mathcal{F C}$ is the log2 fold change of the gene in combustion aerosol compared to clean air control and $\mathcal{J C}$ is the overall impact of chemicals present in aerosol on node $k$. 
For the ranking of genes, we used seven different weighting scenarios iteratively

321 by giving importance to one or other parameters as described above. The major goal was

322 to remove any biasness in selecting top candidate genes responsible for overall dynamics

323 of biological response network that arise due to the parameter values. These weighting

324 scenarios are described in Table 2. After calculating ranking scores in each weighting

325 scenario, top 25 genes were selected and analyzed for their role in regulating biological

326 processes and pathways along with disease association. HFO and DF-specific

327 combustion aerosol networks and top regulatory genes were analyzed using various apps

328 available in Cytoscape v.3.7.1. For example, various topological properties of the

329 networks were analyzed using NetworkAnalyzer release 2.7 [61]; network-disease

330 associations were carried out using DisGeNET App v.4.0 [62,63]; gene-set enrichment

331 analyses on the network were performed using ClueGO [64] and EnricherR [65]. All the

332 statistical analyses were performed using $R$ version 3.0.2 (R Foundation for Statistical

333 Computing, Vienna, Austria).

334 The overall study design comprising experimental and bioinformatics methods is 335 described in Figure 4.

\section{Results}

A total of 100 unique chemicals and 15 broad chemical classes were identified in

338 the online and offline measurements from the HFO and DF exhaust aerosols in various

339 experimental techniques. A comprehensive list of these chemicals and chemical classes

340 along with their concentrations in $\mu \mathrm{g} / \mathrm{m}^{3}$ and respective concentration ratios in HFO and

341 DF aerosol is shown in supplementary figures 1-6 [see Additional file 1]. 
342 All the chemicals and chemical classes were screened for their potential biological 343 targets in human using various state-of-art chemical-gene interaction databases. We 344 could identify biological targets for 52 compounds for which chemical-gene interaction 345 networks were prepared in the standardized Cytoscape compatible format. Further, each 346 of the networks was converted into a fully connected regulatory network by assigning the 347 possible regulatory and functional interactions between the biological partners 348 (gene/protein) using various interaction databases. In particular, the information was 349 collected from interaction databases such as BIND, DIP, HPRD, BIOGRID and STRING. 350 The list of chemicals is provided in table 1.

351 To assign chemicals to a specific combustion aerosol, we set concentration cutoffs for 352 various chemical classes as described in the material and methods section.

353 After prioritization of the aerosol-type specific chemicals based on the concentration 354 cutoff, we could assign 46 chemicals to the HFO and 26 to the DF exhaust aerosol (Table 355 1).

After assigning chemicals to a specific aerosol based on concentration cutoff, we

357 merged individual chemical-gene/protein networks together to construct a comprehensive 358 aerosol-type specific biological response network using merge network app of Cytoscape

359 version 3.7.1. Furthermore, new regulatory connections between biological counterparts 360 were identified and mapped to the network using Cytoscape Bisogenet apps. In case of 361 HFO biological response network, there were in total 780 nodes and 5393 interactions 362 while in DF biological response network, number of nodes and interactions were 512 and 3632631 respectively (Figure 5). 
On aerosols specific biological response networks, we mapped the log2-fold 365 change transcriptomics data from our previously published HFO and DF exposure studies 366 on human bronchial epithelium cell line (BEAS-2B) compared to the respective clean air 367 control[30]. In HFO aerosol-specific biological response network, total 68 genes are found 368 to be differentially regulated candidates (absolute fold change $>1.5$ in comparison to clean 369 air control; 57 genes upregulated and only 11 genes downregulated). In DF biological 370 response network, although less chemicals are present in the aerosol in comparison to 371 HFO-PM, a total of 95 genes were differentially regulated (50 upregulated and 45 372 downregulated) with absolute fold change $>1.5$ in comparison to clean air control.

373 Transcription factors (TFs) play an important role in the regulation of downstream 374 target genes. Biological processes and functions are largely modulated when TFs genes 375 are differentially regulated or TFs are bound to various chemical ligands. Considering this 376 fact, we further identified TFs that are directly regulated by the chemicals present in the 377 aerosols. In HFO biological response network, we found a total of 91 nodes which are 378 known TFs, among them 13 were upregulated while only three were downregulated 379 (absolute FC > 1.5) in comparison to clean air control. Among these TFs, FOS, SNAl1, 380 MYC, JUN, FOSL1 and EGR1 were highly upregulated $(\log (2)$ FC > 1.0); while MDM4, 381 NFIB and MDM2 were downregulated. The DF biological response network contains only 38258 TFs which are directly connected and regulated by various chemicals present in the 383 aerosol. Among them 26 TFs were differentially expressed (absolute FC > 1.5) after the 384 exposure in comparison to clean air control. FOS, SNAI1, MXD1, KLF4, ATF3, EGR1, 385 DDIT3, FOSL1 and NR4A1 were among the highly upregulated TFs $(\log (2)$ FC > 1.0); 
386 while E2F2, NR3C1, NFE2L1 and HIVEP2 were among the highly downregulated $(\log (2)$

387 FC $<-1.0)$ TFs.

388 From the comprehensive aerosol-type specific biological response networks, we 389 identified key nodes responsible for overall network dynamics. For this, we used multi390 objective optimization function as described in Equation 1 using predefined weighting 391 factors assigned to node's topological and non-topological parameters in an iterative 392 manner. From each of the seven weighting scenarios, top 25 genes were selected. 393 Finally, a non-redundant set of nodes was prepared from the matrix of $7 \times 25$ nodes for 394 both HFO (75 genes) and DF (70 genes) biological response networks. Parameters 395 values, ranking scores in seven different weighting scenarios and top ranked candidates 396 are provided in Additional file 2 and 3 for HFO and DF aerosols. Among the top regulatory 397 genes from both HFO and DF biological response network, 37 are shared by both the 398 aerosols.

399 For the differentially regulated nodes connected to aerosol type-specific network, we 400 performed GO analysis for the biological processes and the disease association. We used 401 Cytoscape ClueGO v.2.5.5 for this purpose. Pathways only with $p$-value $\leq 0.05$ were 402 analysed for the enrichment purpose. We consider only those biological processes which 403 have minimum 5 genes or $5 \%$ of the genes among top regulators for HFO and DF 404 respectively. We merged redundant biological processes with $>50 \%$ overlap. Figure 6 405 indicates the overrepresented biological processes by top nodes identified through multi406 objective optimization approach in HFO and DF biological response network. 407 Interestingly, large numbers of immune related processes are overrepresented by the DF 408 network in comparison to HFO. Top regulatory genes in case of DF aerosol exposure are 
409 associated with neuroinflammatory responses, neuronal apoptosis, cell cycle regulation,

410 fibroblast proliferation, production and responses to reactive oxygen species. In case of

411 HFO exposure, top regulatory genes are mainly related to learning processes, neuron

412 death, neurotransmitter receptor activity, placenta development along with the response

413 to reactive oxygen species and oxidative stress.

414 To identify enriched disease terms associated with the top ranked genes in DF and

415 HFO combustion aerosol networks, we used web-based enrichment analysis tool Enrichr

416 [65]. More specifically, we used the DisGeNet library which provides curated data of

417 genes and variants associated with human disease. Figure 7 highlights top 20 disease

418 terms enriched for top ranked genes identified in DF and HFO biological response

419 network. Fibroid tumor is the top enriched disease in case of DF aerosol network with 30

420 associated genes out of 70 top ranked genes. In case of HFO aerosol network,

421 reperfusion injury is the top enriched disease and represented by 24 out of 75 top ranked

422 genes. Apart from several tissue neoplasms, asthma is only enriched in case of DF

423 aerosol network.

\section{Discussion}

425 To identify combustion aerosol-type specific chemicals, we performed 426 chemometric analysis of ship engine exhaust generated from HFO and DF in the online 427 and offline measurements using various experimental techniques described in [32$42834,66,67]$. Identification of chemicals is highly sensitive to the detection limits of various 429 instrumentation facilities. 
The chemicals present in the combustion aerosols interact with biological

431 counterparts (genes, proteins) after exposure and responsible of the perturbation of

432 biological processes and pathways. For this, the information is collected from literatures

433 and public databases which is highly context specific. For a large number of chemical

434 gene interactions in various networks, there were discrepancies on the type of regulations

435 (e.g. activation, suppression, modification, secretion etc.) in biochemical databases. For

436 those ambiguous cases, we manually referred to the original literature and select the most

437 appropriate regulation based on 1) number of studies confirming a specific type of

438 regulation; and 2) the experimental techniques used to predict the interaction type

439 (activation/ suppression).

We hypothesized that the biological responses from the exposure of fuel type-

441 specific ship engine combustion aerosol is due to the chemical entities present in high

442 concentration and their interactions with the biological counterparts in a highly non-linear

443 fashion. For this, we assigned chemicals to either one or both the HFO and DF

444 combustion aerosol depending on their concentration identified in various online/offline

445 chemometric analyses. We understand that the prioritization of chemicals to a particular

446 aerosol simply based on concentration is not the best strategy as some chemicals, when

447 present even in very small quantities, can influence biological systems due to their target

448 specificity and high toxicity. The most appropriate approach to prioritize the chemicals in

449 a combustion aerosol would be based on their permissible exposure limit (PEL) or on

450 other concentration thresholds such as LD50 or EC50 values. However, for many of the

451 chemicals, value of various toxic concentrations (e.g. PEL, LD50 and EC50) is not known

452 and generation of such information has many methodological and technological 
453 challenges. This is the reason why we simply used concentration cut-off for constructing

454 aerosol type-specific biological response networks.

455 As shown in Figure 5, aerosol-specific biological response networks provide a 456 platform to map and visualize experimental data for generating data-driven hypotheses.

457 In this case, we mapped transcriptomics data from BEAS-2B human lung cells exposed 458 to HFO- or DF-operated ship diesel engine exhaust compared to clean air control at air459 liquid interface. The mapping of the data on the aerosol-specific biological response 460 network not only indicated which genes are highly differentially regulated but also hints at 461 the possible regulatory mechanisms responsible for this change. For example, the FOS 462 gene is highly upregulated in both the HFO and DF combustion aerosol. FOS is a proto463 oncogen, plays an important role in many cellular functions and is upregulated in many 464 types of cancer. In case of HFO aerosol-specific biological response network, FOS is 465 directly regulated by 5 chemicals (zinc, chrysene, sulfur dioxide, nitrogen oxide and 466 manganese). While manganese downregulate FOS, other 4 chemicals upregulate it. This 467 suggests that the combined effect of 4 chemicals upregulating FOS is much higher than 468 the manganese. In case of DF aerosol-specific biological response network, FOS is 469 upregulated and connected with only two chemicals (chrysene and nitrogen oxide). 470 Interestingly, the expression of FOS is much higher in DF than HFO when both the 471 aerosols are individually compared to clean air control. It may be due to the presence of 472 one negative regulator for FOS (manganese) in HFO aerosol. The BBOX1 was the most 473 significantly downregulated gene in HFO biological response network due to the presence 474 of Aluminium which is known for the downregulation of this gene expression [68]. These 475 analyses indicate that aerosol-specific biological response networks as generated in this 
476 work could help to decipher mechanisms associated with combined effect of chemical

477 entities present in aerosols. The mapping of the transcriptomics data onto the network

478 also indicate that large number of TFs are differentially regulated due to the exposure of

479 DF aerosol $(n=26)$ in comparison to clean air control, while in case of HFO, only 16 TFs

480 are differentially regulated. These observations also suggest that exposure to DF aerosol

481 may have more intense biological responses in comparison to HFO aerosol even though

482 large number of chemicals were identified exclusively in HFO aerosol.

483 We also ranked genes/proteins present in the aerosol-specific biological response

484 network using various topological and non-topological parameters. Among the topological

485 parameters, we mainly considered node degree, betweenness centrality and clustering

486 coefficient as these parameters points towards the hub node, the gate keeper for

487 information flow and the probability of forming clusters respectively. For non-topological

488 parameters, we considered aerosol-type specific expression fold change compared to

489 clean air control. Expression profile of a gene is highly dynamic in nature which largely

490 depends on the context and concentration of its regulators. In case of HFO and DF

491 combustion aerosols, for many chemicals the value significantly varies between two

492 aerosols despite concentrations distinct above the cut-off. To consider the concentration

493 of chemicals into the account for analyzing biological responses, we calculated "Overall

494 impact of chemicals" on each of the genes/proteins present in aerosol-type specific 495 network considering total number of genes/ proteins regulated by a chemical. Amount of

496 chemical was then equally distributed among the connected genes/proteins to calculate

497 a scaling factor for each chemical. Finally, for each of the gene/protein combined impact

498 of all the chemicals was calculated by summing up of scaling factors of each of the 
499 connected chemicals along with their regulation directions (for detail, please see the

500 algorithms described in the material and method section). Combining "Overall impact of

501 chemicals" with topological and non-topological parameters along with various weighting

502 scenarios, we ranked nodes using the equation -1 iteratively. Furthermore, selecting top

50325 nodes in each of the weighting scenarios, we identified key regulators that influence

504 to overall network dynamics were identified. Considering different weight to different

505 parameters (Table 2), we removed any biasness associated with topological / non-

506 topological parameters in selecting top ranked nodes.

\section{Conclusion}

508 Identification and assessment of biological responses from the exposure to complex

509 mixtures of chemicals such as in combustion aerosols is challenging due to multiple

510 nonlinear regulations among the genes and proteins. The combined effect may be

511 evaluated by mapping all the possible known regulations (up or down regulation) of

512 individual chemicals among the connected nodes. In this manuscript, we provide a

513 workflow to construct aerosol-type specific biological response networks (Figure 3) using

514 the chemical fingerprint of the aerosols as input. This workflow integrates various steps

515 to design a comprehensive chemical-biological association networks in a systematic way

516 to reveal potential molecular mechanisms associated with the exposure of mixture of

517 chemicals. We provide an exemplary algorithm to estimate the combined regulatory effect

518 of chemicals on genes/protein present in the network. The knowledgebase generated in

519 this manuscript for the example of the emission of a ship engine operated either with

520 diesel fuel or heavy fuel oil provides 52 chemical-gene/protein regulatory networks which

521 can be used for preparation and analyses of biological response network associated with 
522 a chemical or mixture of chemicals. The here developed strategy can be used to evaluate

523 the health impact of different aerosols based on their chemical fingerprint and chemical

524 fingerprint.

525 If we consider the investigated ship engine emission aerosols, the study reveals the large

526 differences in the observed biological effects caused by operating of the ship engine on

527 the different fuels. This motivates to thoroughly investigate the impact of the chemical

528 composition of the ship fuel on the potential health effects because the current IMO

529 legislation has a tremendous impact on the composition of future shipping fuels. Since

5302020 , the so called IMO "Sulfur Cap" legislation banns fuels with more than $0.5 \%$ sulphur.

531 These conventional residual fuels (i.e. HFO's) with typical sulfur contents between 1.5

532 and $3.5 \%$ can only be used if sulphur emission control technologies (i.e. so called

533 "scrubbers"), which however are rarely implemented yet, are used. Thus it is expected

534 that new fuels (desulfurized HFO's, sulfur lean but highly aromatic refining fractions etc.)

535 will come to the market [69]. The here presented approach might be utilized for the

536 evaluation of the relative health risk of the emission associated with the use of the new

537 shipping fuels.

538 Declarations

539 Ethics approval and consent to participate

$540 \quad$ Not applicable

541 Consent for publication

$542 \quad$ Not applicable

543 Availability of data and materials 
The transcriptomics datasets analysed during the current study are available in the

545 Gene Expression Omnibus (GSE63962). All other data generated or analysed during this 546 study are included in this published article and its supplementary information files.

548 Competing interests

549 The authors declare that they have no competing interests.

$551 \quad$ Funding

552 The funding of the study is based public project funding and the base funding of the 553 participation organization.

555 Authors' contributions

556 RZ, OW, SSG, SG and TS conceptualized the workplan. SSG constructed and 557 analyzed aerosol-specific biological response network. SSG, SG and OW prepared the 558 algorithm for prioritization of nodes in the network. SSG, RZ and TS wrote the first draft. 559 SO, HC, JP, MS, OP, JJ, MH, GD, TK, JB, BS, HH, MD, CS, KH, SS and RZ performed 560 offline and online chemometric analysis of combustion aerosols. All authors reviewed and 561 finalized the manuscript.

\section{Acknowledgements}

564 Funding by the Helmholtz Association (HGF), Berlin Germany for the

565 a) Helmholtz Virtual Institute HICE - Aerosol and Health and

b) Helmholtz International Lab aeroHEALTH 
is gratefully acknowledged.

\section{References}

570 1. Heys KA, Shore RF, Pereira MG, Jones KC, Martin FL. Risk assessment of environmental mixture effects. RSC Adv. 2016;6:47844-57.

572 2. Altenburger R, Scholz S, Schmitt-Jansen M, Busch W, Escher BI. Mixture toxicity revisited from a 573 toxicogenomic perspective. Environ Sci Technol. 2012;46:2508-22.

574 3. Backhaus T, Faust M. Predictive environmental risk assessment of chemical mixtures: A conceptual 575 framework. Environ Sci Technol. 2012;46:2564-73.

576 4. Hernández AF, Gil F, Tsatsakis AM. Biomarkers of chemical mixture toxicity. Biomarkers Toxicol. 577 2014;655-69.

578 5. Liu S, Zhang J, Zhang Y, Qin L. Aptox: Assessment and prediction on toxicity of chemical mixtures. Acta 579 Chim Sin. 2012;70:1511-7.

580 6. Warne MS, Hawker DW. The number of components in a mixture determines whether synergistic and antagonistic or additive toxicity predominate: the funnel hypothesis. Ecotoxicol. Environ. Saf. 1995. p. 238.

7. Ho SM, Johnson A, Tarapore P, Janakiram V, Zhang X, Leung YK. Environmental epigenetics and its implication on disease risk and health outcomes. ILAR J. 2012;53:289-305.

8. Gatzidou ET, Zira AN, Theocharis SE. Toxicogenomics: A pivotal piece in the puzzle of toxicological research. J Appl Toxicol. 2007;27:302-9.

587 9. Nesnow S. Integration of toxicological approaches with "omic" and related technologies to elucidate 588 mechanisms of carcinogenic action: Propiconazole, an example. Cancer Lett. 2013;334:20-7.

10. Sturla SJ, Boobis AR, Fitzgerald RE, Hoeng J, Kavlock RJ, Schirmer K, et al. Systems toxicology: From basic research to risk assessment. Chem Res Toxicol. 2014;27:314-29.

11. Boelsterli UA. Mechanistic Toxicology: The Molecular Basis of How Chemicals Disrupt Biological Targets [Internet]. 2nd ed. Boelsterli UA, editor. Taylor Fr. CRC Press, Taylor \& Francis Group; 2003. Available from: http://books.google.com/books?hl=en\&lr=\&id=lyFplWr1H1MC\&oi=fnd\&pg=PA1\&dq=Mechanistic+toxicolo gy+:+the+molecular+basis+of+how+chemicals+disrupt+biological+targets\&ots=2yBeUKp6u5\&sig=AsHn QBSg7loeqZb2yuf4qPwSVdw\%5Cnhttp://www.worldcat.org/oclc/53003932 environmental chemicals that enable the cancer hallmark of evasion of growth suppression. Carcinogenesis. 2015;36:S2-18. instability: The effect of low dose chemical exposures in modern society. Carcinogenesis. 2015;36:S6188.

603 14. Skinner MK. Environmental epigenomics and disease susceptibility. EMBO Rep. 2011;12:620-2.

604 15. Kennedy IM. The health effects of combustion-generated aerosols. Proc Combust Inst. 2007;31 605 II:2757-70. 
16. Dellinger B, Pryor WA, Cueto R, Squadrito GL, Deutsch WA. The role of combustion-generated radicals in the toxicity of PM2.5. Proc Combust Inst. 2000;28:2675-81.

608 17. Streibel T, Schnelle-Kreis J, Czech H, Harndorf H, Jakobi G, Jokiniemi J, et al. Aerosol emissions of a 609 ship diesel engine operated with diesel fuel or heavy fuel oil. Environ Sci Pollut Res. 2017;24:10976-91.

610 18. Corbin JC, Mensah AA, Pieber SM, Orasche J, Michalke B, Zanatta M, et al. Trace Metals in Soot and 611 PM2.5 from Heavy-Fuel-Oil Combustion in a Marine Engine. Environ Sci Technol. 2018;52:6714-22.

612 19. Corbett JJ, Winebrake JJ, Green EH, Kasibhatla P, Eyring V, Lauer A. Mortality from ship emissions: A 613 global assessment. Environ Sci Technol. 2007;41:8512-8.

614 20. Tian L, Ho K fai, Louie PKK, Qiu H, Pun VC, Kan H, et al. Shipping emissions associated with increased 615 cardiovascular hospitalizations. Atmos Environ. 2013;74:320-5.

616 21. Abadie LM, Goicoechea N, Galarraga I. Adapting the shipping sector to stricter emissions regulations: 617 Fuel switching or installing a scrubber? Transp Res Part D Transp Environ. 2017;57:237-50.

618 22. Endres S, Maes F, Hopkins F, Houghton K, Mårtensson EM, Oeffner J, et al. A new perspective at the 619 ship-air-sea-interface: The environmental impacts of exhaust gas scrubber discharge. Front Mar Sci. $620 \quad 2018 ; 5$.

621 23. Winnes H, Granberg M, Magnusson K, Malmaeus M, Mellin A, Stripple H, et al. Scrubbers: Closing the 622 loop Activity 3: Summary Environmental analysis of marine exhaust gas scrubbers on two Stena Line ships 623 [Internet]. IVL Swedish Environ. Res. Inst. 2018. Available from: 624 https://www.ivl.se/download/18.20b707b7169f355daa775fc/1561358335876/B2317.pdf

625 24. Winnes H, Fridell E, Moldanová J. Effects of marine exhaust gas scrubbers on gas and particle 626 emissions. J Mar Sci Eng. 2020;

627 25. Sofiev M, Winebrake JJ, Johansson L, Carr EW, Prank M, Soares J, et al. Cleaner fuels for ships 628 provide public health benefits with climate tradeoffs. Nat Commun. 2018;9.

629 26. Viana M, Fann N, Tobías A, Querol X, Rojas-Rueda D, Plaza A, et al. Environmental and health benefits 630 from designating the marmara sea and the turkish straits as an emission control area (ECA). Environ Sci 631 Technol. 2015;49:3304-13.

632 27. Brandt J, Silver JD, Christensen JH, Andersen MS, Bønløkke JH, Sigsgaard T, et al. Assessment of 633 past, present and future health-cost externalities of air pollution in Europe and the contribution from 634 international ship traffic using the EVA model system. Atmos Chem Phys. 2013;13:7747-64.

635 28. Winebrake JJ, Corbett JJ, Green EH, Lauer A, Eyring V. Mitigating the health impacts of pollution from 636 oceangoing shipping: An assessment of low-sulfur fuel mandates. Environ Sci Technol. 2009;43:4776-82.

637 29. Wichmann HE. Diesel exhaust particles. Inhal Toxicol. 2007;19:241-4.

638 30. Oeder S, Kanashova T, Sippula O, Sapcariu SC, Streibel T, Arteaga-Salas JM, et al. Particulate matter 639 from both heavy fuel oil and diesel fuel shipping emissions show strong biological effects on human lung 640 cells at realistic and comparable in vitro exposure conditions. PLoS One. 2015;10.

641 31. Sapcariu SC, Kanashova T, Dilger M, Diabaté S, Oeder S, Passig J, et al. Metabolic profiling as well 642 as stable isotope assisted metabolic and proteomic analysis of RAW 264.7 macrophages exposed to ship 643 engine aerosol emissions: Different effects of heavy fuel oil and refined diesel fuel. PLoS One. 2016;11.

644 32. Rüger CP, Sklorz M, Schwemer T, Zimmermann R. Characterisation of ship diesel primary particulate 645 matter at the molecular level by means of ultra-high-resolution mass spectrometry coupled to laser 646 desorption ionisation - Comparison of feed fuel, filter extracts and direct particle measurements. Anal 647 Bioanal Chem. 2015;407:5923-37. 
33. Moldanová J, Fridell E, Popovicheva O, Demirdjian B, Tishkova V, Faccinetto A, et al. Characterisation of particulate matter and gaseous emissions from a large ship diesel engine. Atmos Environ. 2009;43:263241.

34. Kleeblatt J, Schubert JK, Zimmermann R. Detection of gaseous compounds by needle trap sampling and direct thermal-desorption photoionization mass spectrometry: Concept and demonstrative application to breath gas analysis. Anal Chem. 2015;87:1773-81.

35. Radischat C, Sippula O, Stengel B, Klingbeil S, Sklorz M, Rabe R, et al. Real-time analysis of organic compounds in ship engine aerosol emissions using resonance-enhanced multiphoton ionisation and proton transfer mass spectrometry Aerosols and Health. Anal Bioanal Chem. 2015;407:5939-51.

36. Czech H, Stengel B, Adam T, Sklorz M, Streibel T, Zimmermann R. A chemometric investigation of aromatic emission profiles from a marine engine in comparison with residential wood combustion and road traffic: Implications for source apportionment inside and outside sulphur emission control areas. Atmos Environ. 2017;167:212-22.

37. Sippula O, Stengel B, Sklorz M, Streibel T, Rabe R, Orasche J, et al. Particle emissions from a marine engine: Chemical composition and aromatic emission profiles under various operating conditions. Environ Sci Technol. 2014;48:11721-9.

38. Mülhopt S, Dilger M, Diabaté S, Schlager C, Krebs T, Zimmermann R, et al. Toxicity testing of combustion aerosols at the air-liquid interface with a self-contained and easy-to-use exposure system. $J$ Aerosol Sci. 2016;96:38-55.

39. Iskandar AR, Gonzalez-Suarez I, Majeed S, Marescotti D, Sewer A, Xiang Y, et al. A framework for in vitro systems toxicology assessment of e-liquids. Toxicol Mech Methods. 2016;26:389-413.

40. Smith MR, Clark B, Lüdicke F, Schaller JP, Vanscheeuwijck P, Hoeng J, et al. Evaluation of the Tobacco Heating System 2.2. Part 1: Description of the system and the scientific assessment program. Regul Toxicol Pharmacol. 2016;81:S17-26.

41. Zimmermann R. Aerosols and health: A challenge for chemical and biological analysis. Anal Bioanal Chem. 2015;407:5863-7.

42. Orasche J, Schnelle-Kreis J, Abbaszade G, Zimmermann R. Technical Note: In-situ derivatization thermal desorption GC-TOFMS for direct analysis of particle-bound non-polar and polar organic species. Atmos Chem Phys. 2011;11:8977-93.

43. Reda AA, Schnelle-Kreis J, Orasche J, Abbaszade G, Lintelmann J, Arteaga-Salas JM, et al. Gas phase carbonyl compounds in ship emissions: Differences between diesel fuel and heavy fuel oil operation. Atmos Environ. 2015;112:370-80.

44. Radischat C, Sippula O, Stengel B, Klingbeil S, Sklorz M, Rabe R, et al. Real-time analysis of organic compounds in ship engine aerosol emissions using resonance-enhanced multiphoton ionisation and proton transfer mass spectrometry Aerosols and Health. Anal Bioanal Chem. 2015;407:5939-51.

45. Davis AP, Grondin CJ, Lennon-Hopkins K, Saraceni-Richards C, Sciaky D, King BL, et al. The Comparative Toxicogenomics Database's 10th year anniversary: Update 2015. Nucleic Acids Res. 2015;43:D914-20.

46. Gaulton A, Bellis LJ, Bento AP, Chambers J, Davies M, Hersey A, et al. ChEMBL: A large-scale bioactivity database for drug discovery. Nucleic Acids Res. 2012;40.

47. Wang Y, Bryant SH, Cheng T, Wang J, Gindulyte A, Shoemaker BA, et al. PubChem BioAssay: 2017 update. Nucleic Acids Res. 2017;45:D955-63.

48. Szklarczyk D, Santos A, Von Mering C, Jensen LJ, Bork P, Kuhn M. STITCH 5: Augmenting protein- 
chemical interaction networks with tissue and affinity data. Nucleic Acids Res. 2016;44:D380-4.

692 49. Dix DJ, Houck KA, Martin MT, Richard AM, Setzer RW, Kavlock RJ. The toxcast program for prioritizing 693 toxicity testing of environmental chemicals. Toxicol Sci. 2007;95:5-12.

694 50. Franceschini A, Szklarczyk D, Frankild S, Kuhn M, Simonovic M, Roth A, et al. STRING v9.1: Protein695 protein interaction networks, with increased coverage and integration. Nucleic Acids Res. 2013;41.

696 51. Keshava Prasad TS, Goel R, Kandasamy K, Keerthikumar S, Kumar S, Mathivanan S, et al. Human Protein Reference Database - 2009 update. Nucleic Acids Res. 2009;37:D767-72.

698 52. Shannon P, Markiel A, Ozier O, Baliga NS, Wang JT, Ramage D, et al. Cytoscape: A software Environment for integrated models of biomolecular interaction networks. Genome Res. 2003;13:2498-504.

53. Nepusz T, Yu H, Paccanaro A. Detecting overlapping protein complexes in protein-protein interaction 701 networks. Nat Methods. 2012;9:471-2.

702 54. Xenarios I. DIP: the Database of Interacting Proteins. Nucleic Acids Res. 2000;28:289-91.

703 55. Gilbert D. Biomolecular interaction network database. Brief Bioinform. 2005;6:194-8.

704

705
56. Ritchie ME, Phipson B, Wu D, Hu Y, Law CW, Shi W, et al. limma powers differential expression analyses for RNA-sequencing and microarray studies. Nucleic Acids Res. England; 2015;43:e47.

57. Khan FM, Gupta SK, Wolkenhauer O. Integrative workflows for network analysis. Essays Biochem. 2018;62:549-61.

58. Khan FM, Marquardt S, Gupta SK, Knoll S, Schmitz U, Spitschak A, et al. Unraveling a tumor typespecific regulatory core underlying E2F1-mediated epithelial-mesenchymal transition to predict receptor protein signatures. Nat Commun. 2017;8:198.

59. Singh N, Eberhardt M, Wolkenhauer O, Vera J, Gupta SK. An integrative network-driven pipeline for systematic identification of IncRNA-associated regulatory network motifs in metastatic melanoma. BMC Bioinformatics. 2020;21.

60. Serhan CN, Gupta SK, Perretti M, Godson C, Brennan E, Li Y, et al. The Atlas of Inflammation Resolution (AIR). Mol Aspects Med. 2020;74:100894.

61. Assenov Y, Ramírez F, Schelhorn SESE, Lengauer T, Albrecht M. Computing topological parameters of biological networks. Bioinformatics. 2008;24:282-4.

62. Piñero J, Queralt-Rosinach N, Bravo À, Deu-Pons J, Bauer-Mehren A, Baron M, et al. DisGeNET: A discovery platform for the dynamical exploration of human diseases and their genes. Database. 2015;2015.

63. Bauer-Mehren A, Rautschka M, Sanz F, Furlong LI. DisGeNET: A Cytoscape plugin to visualize, integrate, search and analyze gene-disease networks. Bioinformatics. 2010;26:2924-6.

64. Mlecnik B, Galon J, Bindea G. Comprehensive functional analysis of large lists of genes and proteins. J Proteomics. 2018;171:2-10.

65. Kuleshov M V., Jones MR, Rouillard AD, Fernandez NF, Duan Q, Wang Z, et al. Enrichr: a comprehensive gene set enrichment analysis web server 2016 update. Nucleic Acids Res. 2016;44:W907.

66. Czech H, Sippula O, Kortelainen M, Tissari J, Radischat C, Passig J, et al. On-line analysis of organic emissions from residential wood combustion with single-photon ionisation time-of-flight mass spectrometry (SPI-TOFMS). Fuel. 2016;177:334-42. 
67. Weggler BA, Ly-Verdu S, Jennerwein M, Sippula O, Reda AA, Orasche J, et al. Untargeted Identification of Wood Type-Specific Markers in Particulate Matter from Wood Combustion. Environ Sci Technol. American Chemical Society; 2016;50:10073-81.

68. Lemire J, Mailloux R, Darwich R, Auger C, Appanna VD. The disruption of l-carnitine metabolism by aluminum toxicity and oxidative stress promotes dyslipidemia in human astrocytic and hepatic cells. Toxicol Lett. 2011;203:219-26.

69. Käfer U, Gröger T, Rohbogner CJ, Struckmeier D, Saraji-Bozorgzad MR, Wilharm T, et al. Detailed Chemical Characterization of Bunker Fuels by High-Resolution Time-of-Flight Mass Spectrometry Hyphenated to GC × GC and Thermal Analysis. Energy and Fuels. 2019;33:10745-55.

\section{Figures \& Tables}

Figure 1: Schematic representation of possible toxicity outcomes of two chemicals $(A \& B)$ alone and in a mixture.

Chemicals when present together in an exposure matrix can show the synergism, addition, antagonism or inhibition in the overall toxicity outcomes. The simplest assumption is the concentration addition where the overall toxicity of the mixture can be calculated by addition of toxicity caused by chemicals individually. However, due to the complex regulatory events in a biological system, chemicals in an exposure matrix mostly show the synergism or antagonism where the overall toxicity is either more or less than the concentration addition. Sometime chemicals, when present together in an exposure matrix, inhibit each other or form a composite which is less toxic than the parent compounds.

Figure 2: Possible mechanisms for combustion aerosols exposure induced carcinogenesis, cardiovascular and lung pathogenesis.

Chemical, metals, fibers and particulate matter released from ship/automobile exhausts, industrial exhaust or wood combustion can generate oxidative stress in the exposed cells, which may lead to various chronic conditions including carcinogenesis, cardiovascular and lung diseases. Other possible effects might be through frustrated phagocytosis in macrophages (more relevant for fibers) which may induce chronic inflammations. Chemicals present in combustion aerosols may also cause genotoxicity by interfering in DNA methylation, histone modification or DNA strand breakage. Chemical entities present in combustion aerosols also form complexes with altogether different toxicity profiles than the parent compounds. Most often these complexes increase the bioavailability of toxic chemicals by slow and sustain release inside the cell.

\section{Figure 3: Workflow for constructing aerosol-type specific chemical - gene} interaction regulatory network 
Figure 4: Overall experimental and bioinformatic flowchart of this study. blue shaded: - experimental workflow aspects, green shaded: big data/bioinformatic workflow aspects)

Figure 5: Aerosol-type specific biological response networks.

(a) HFO-combustion aerosol; (b) DF-combustion aerosol. Chemicals are shown as red color triangles, biological components (gene, protein, mRNA etc.) are shown as blue color nodes. Size of the node reflects node degree (i.e. number of connections from a node to other nodes). For the readability, nodes with node degree $>25$ are labeled. Red lines are inhibition and green ones are activation from source to target nodes while blue color lines are protein-protein interaction without the regulatory directions.

Figure 6: Biological processes associated with top regulators in (a) HFO; and (b) DF biological response network. Nodes depict over-represented terms; colors reflect the label of the most significant term per group

Figure 7: Enriched disease terms for top ranked genes in (A) DF and (B) HFO aerosol network. The gene-disease interaction matrices are created using the Enrichr tool. Rows are top ranked genes in DF and HFO network, while columns are enriched disease terms arranged based on the combined score which is a combination of $p$-value and z-score to rank enriched disease terms. The length of the colored bar with disease name represents the significance of disease terms with respect to the associated genes.

791 The colored cells in the matrix indicates that the corresponding gene-disease association.

Table 1: List of compounds having molecular interaction network and their aerosol-type 794 specificity. response network 


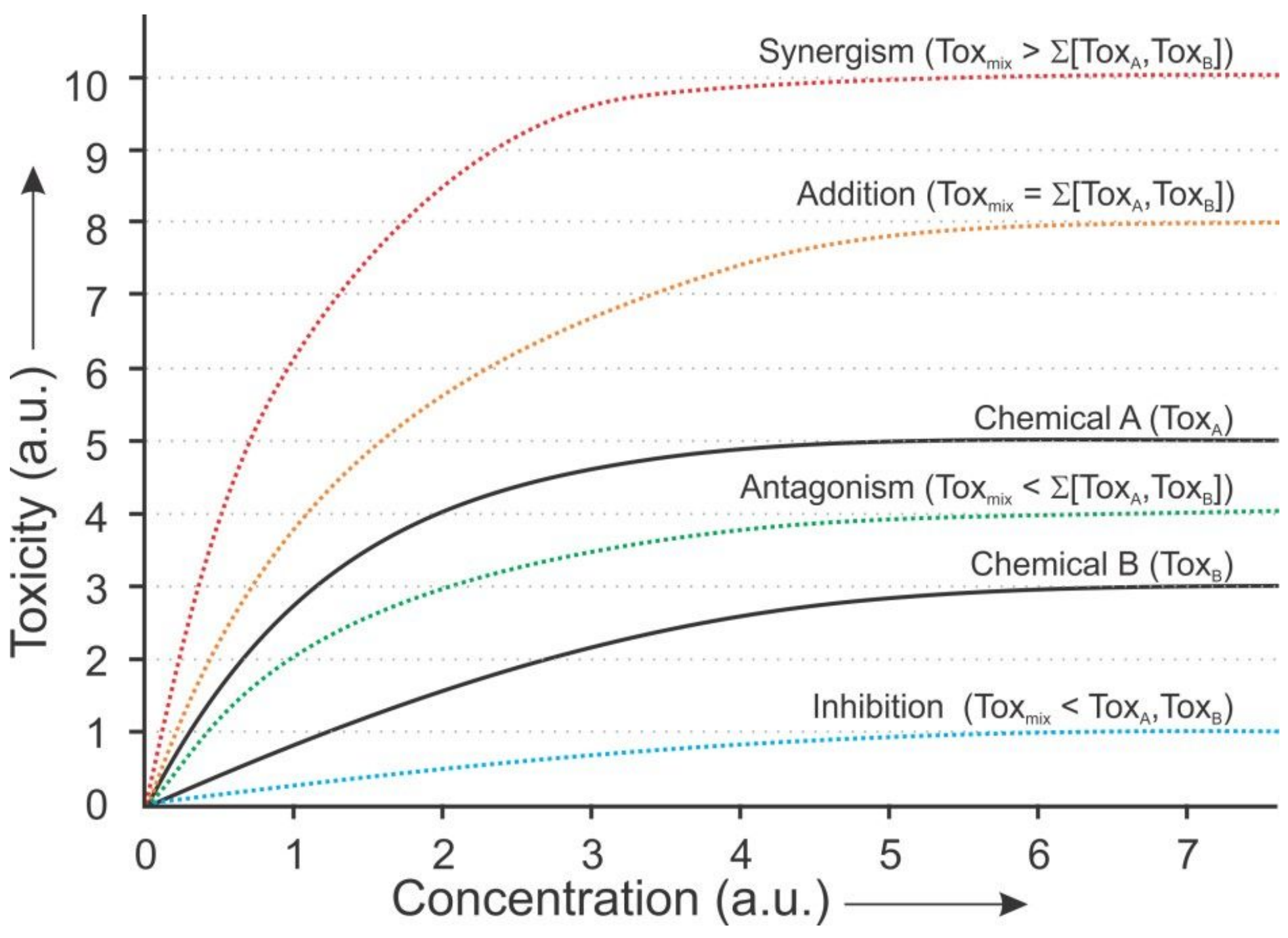

\section{Figure 1}

Schematic representation of possible toxicity outcomes of two chemicals (A \& B) alone and in a mixture. Chemicals when present together in an exposure matrix can show the synergism, addition, antagonism or inhibition in the overall toxicity outcomes. The simplest assumption is the concentration addition where the overall toxicity of the mixture can be calculated by addition of toxicity caused by chemicals individually. However, due to the complex regulatory events in a biological system, chemicals in an exposure matrix mostly show the synergism or antagonism where the overall toxicity is either more or less than the concentration addition. Sometime chemicals, when present together in an exposure matrix, inhibit each other or form a composite which is less toxic than the parent compounds. 

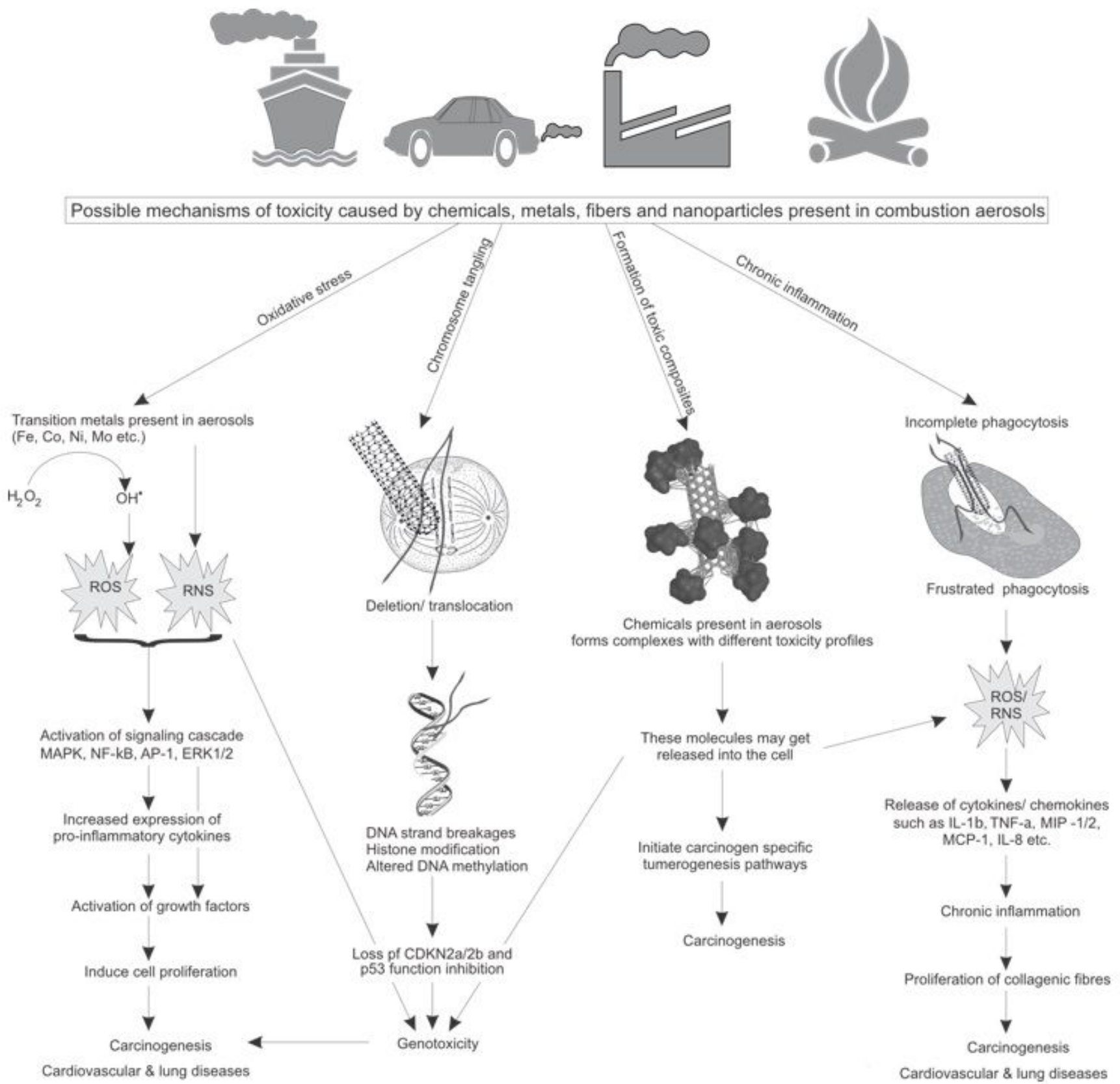

\section{Figure 2}

Possible mechanisms for combustion aerosols exposure induced carcinogenesis, cardiovascular and lung pathogenesis. Chemical, metals, fibers and particulate matter released from ship/automobile exhausts, industrial exhaust or wood combustion can generate oxidative stress in the exposed cells, which may lead to various chronic conditions including carcinogenesis, cardiovascular and lung diseases. Other possible effects might be through frustrated phagocytosis in macrophages (more relevant for fibers) which may induce chronic inflammations. Chemicals present in combustion aerosols may also cause genotoxicity by interfering in DNA methylation, histone modification or DNA strand breakage. Chemical entities present in combustion aerosols also form complexes with altogether 
different toxicity profiles than the parent compounds. Most often these complexes increase the bioavailability of toxic chemicals by slow and sustain release inside the cell.

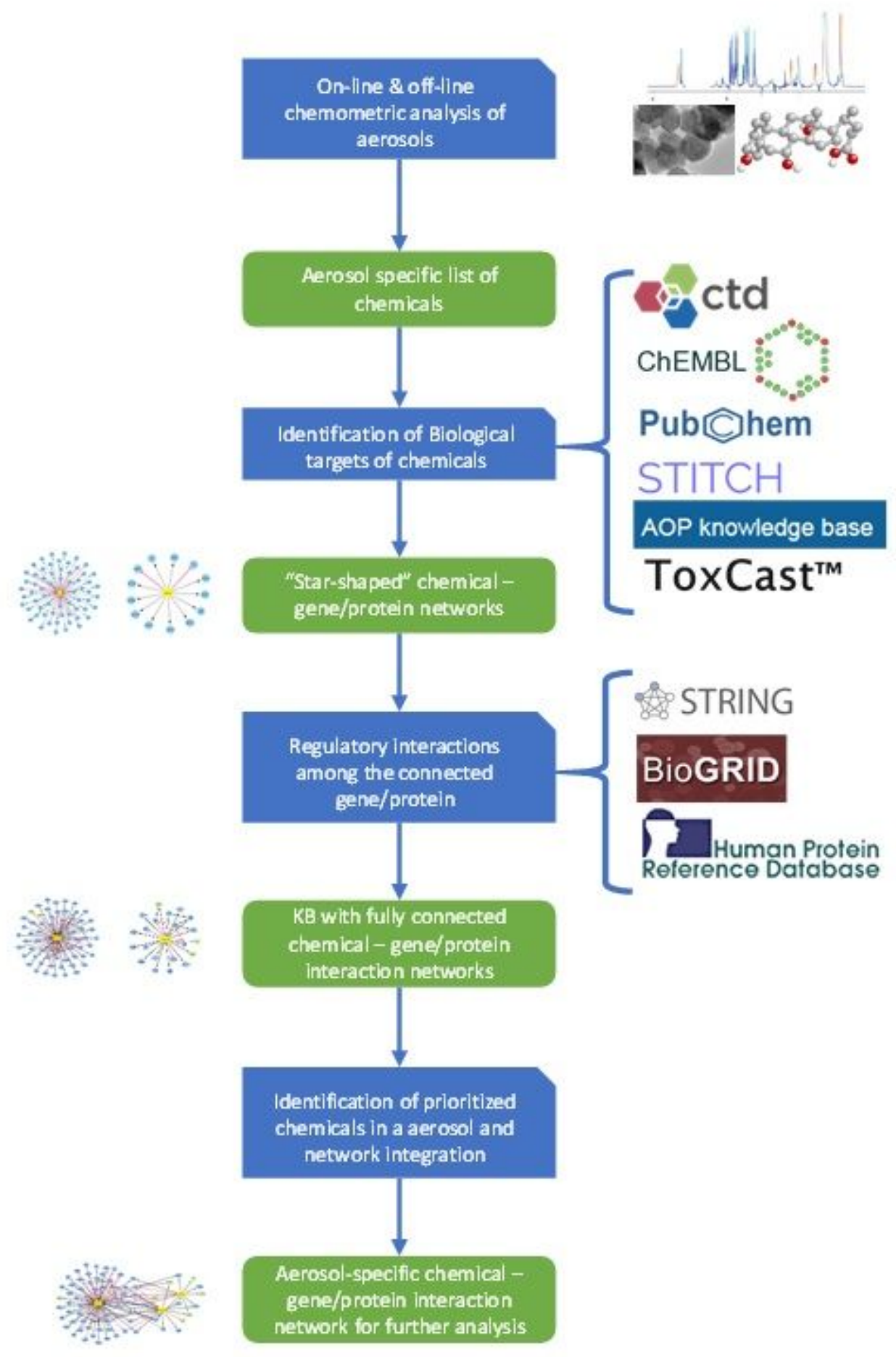

Figure 3

Workflow for constructing aerosol-type specific chemical - gene interaction regulatory network 


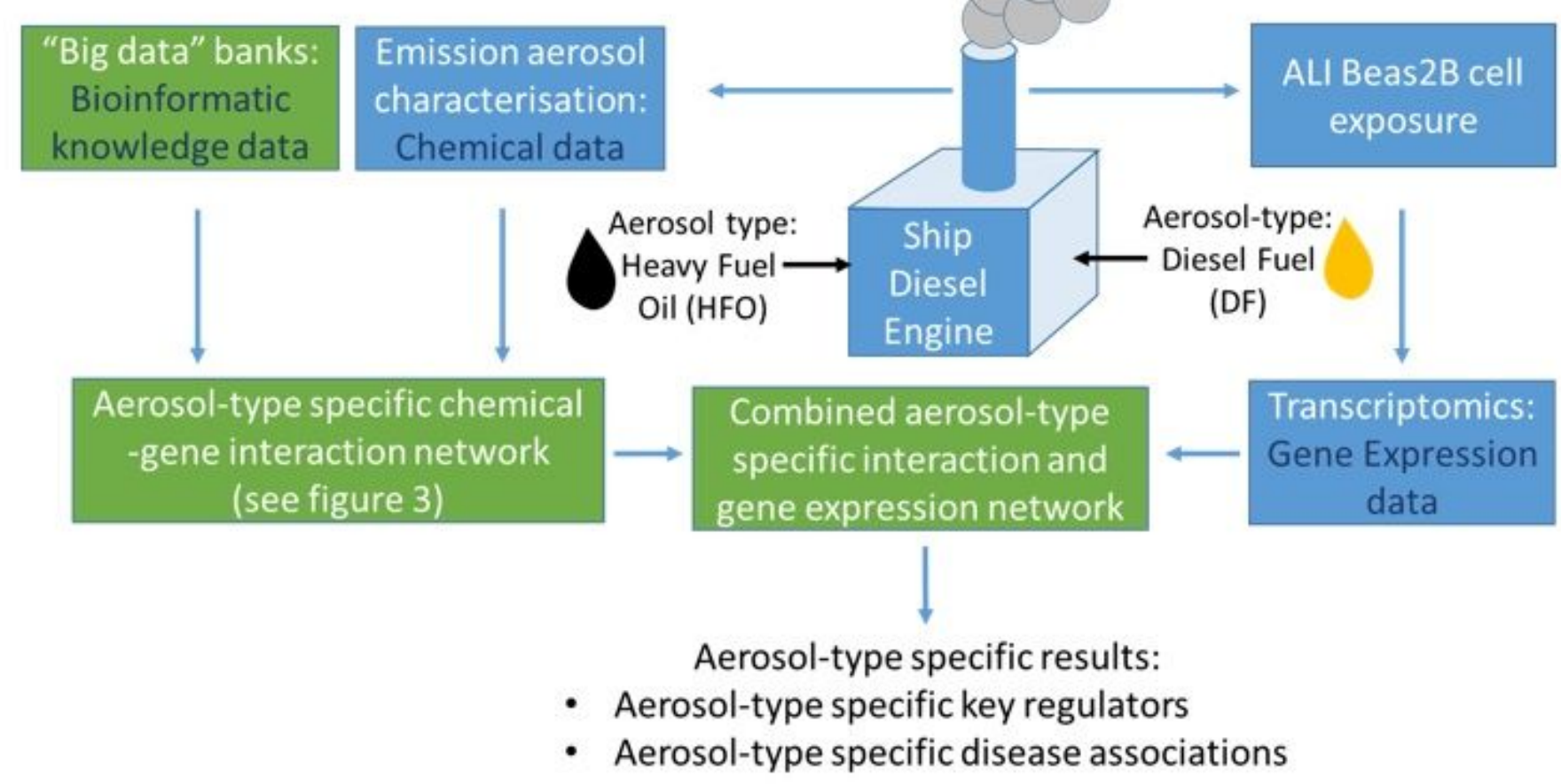

Figure 4

Overall experimental and bioinformatic flowchart of this study. blue shaded: - experimental workflow aspects, green shaded: big data/bioinformatic workflow aspects)

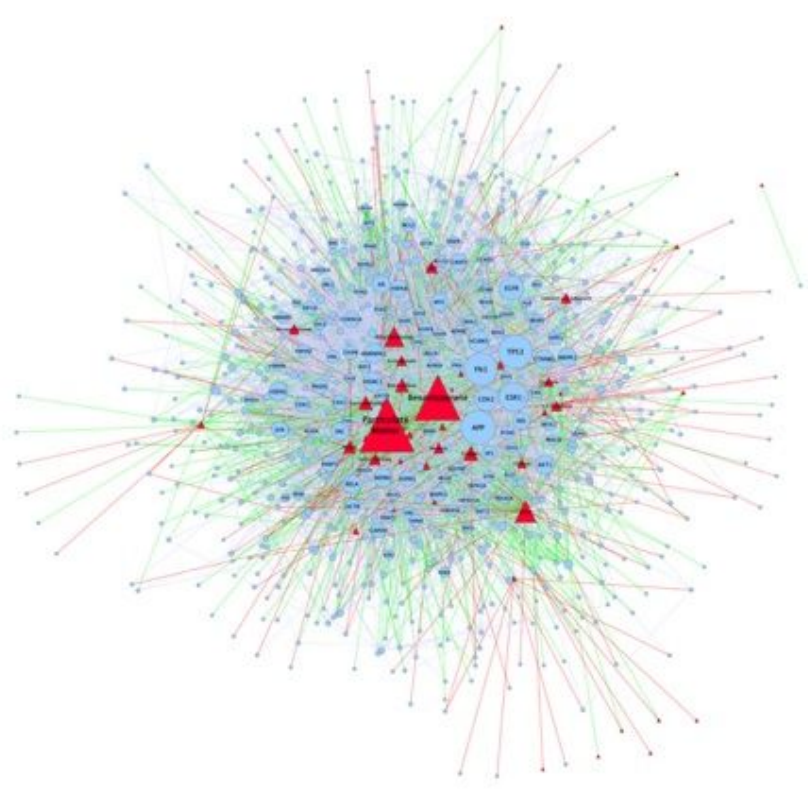

(a) HFO

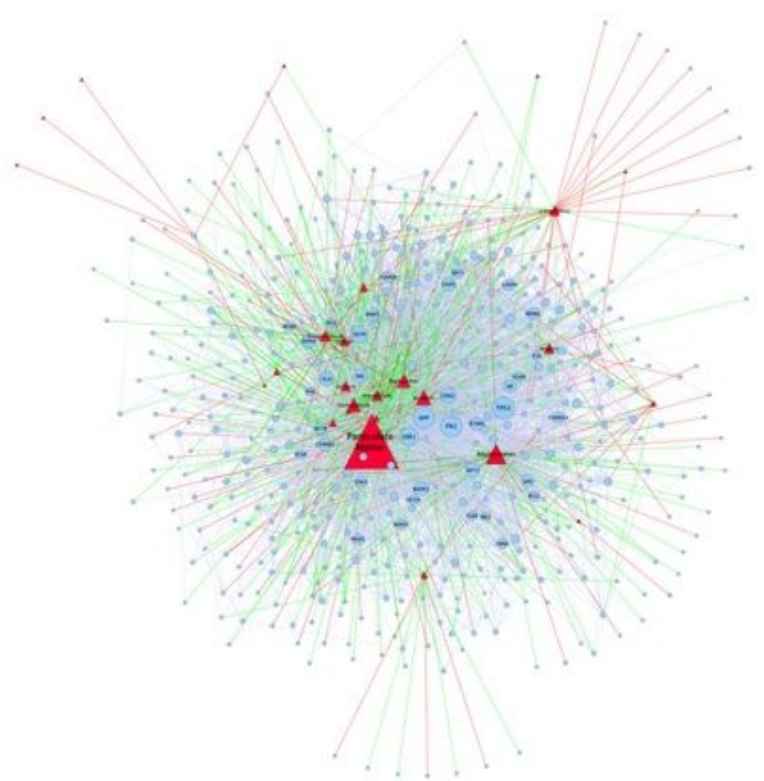

(b) DF 


\section{Figure 5}

Aerosol-type specific biological response networks. (a) HFO-combustion aerosol; (b) DF-combustion aerosol. Chemicals are shown as red color triangles, biological components (gene, protein, mRNA etc.) are shown as blue color nodes. Size of the node reflects node degree (i.e. number of connections from a node to other nodes). For the readability, nodes with node degree $>25$ are labeled. Red lines are inhibition and green ones are activation from source to target nodes while blue color lines are protein-protein interaction without the regulatory directions.

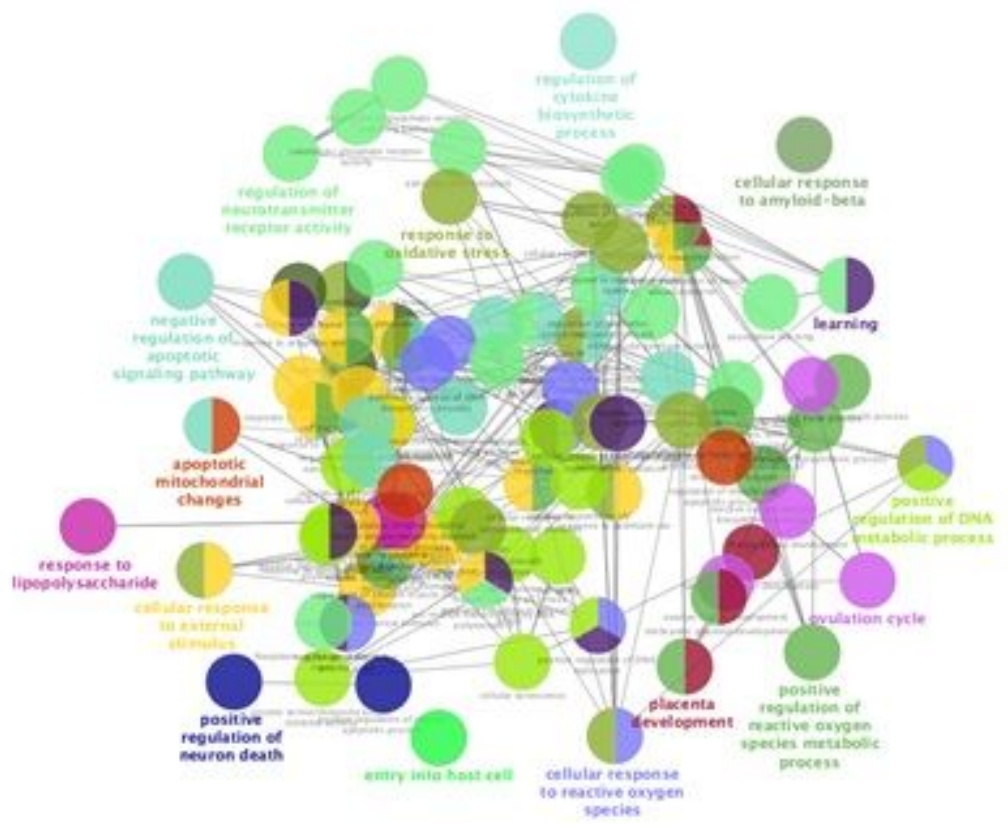

(a)

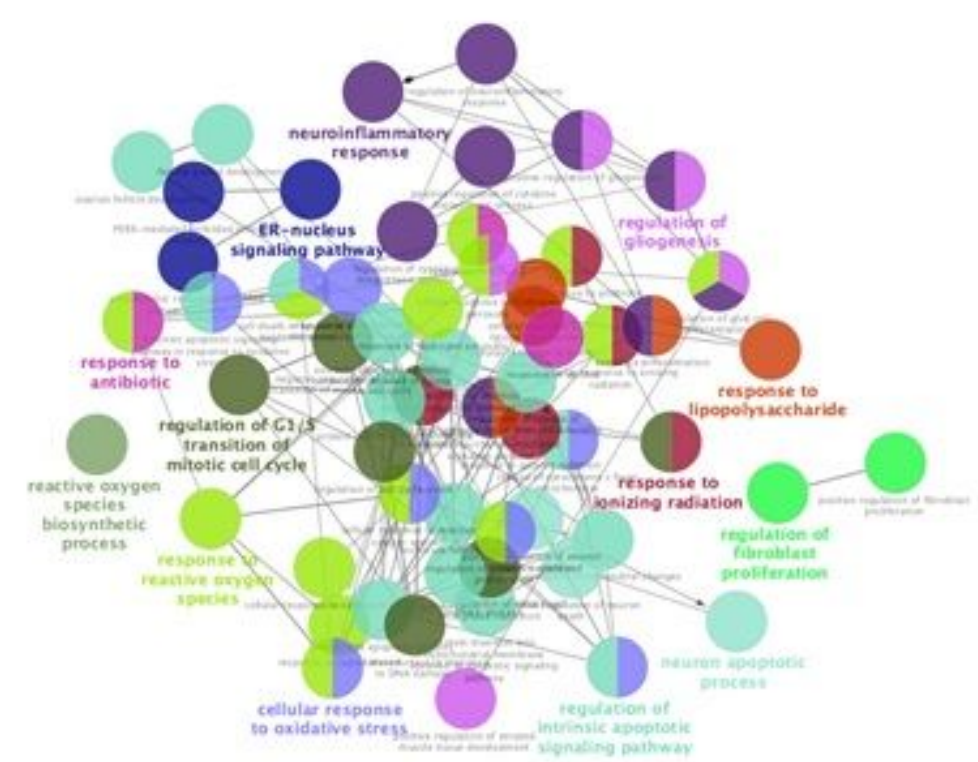

(b) 
Biological processes associated with top regulators in (a) HFO; and (b) DF biological response network. Nodes depict over-represented terms; colors reflect the label of the most significant term per group

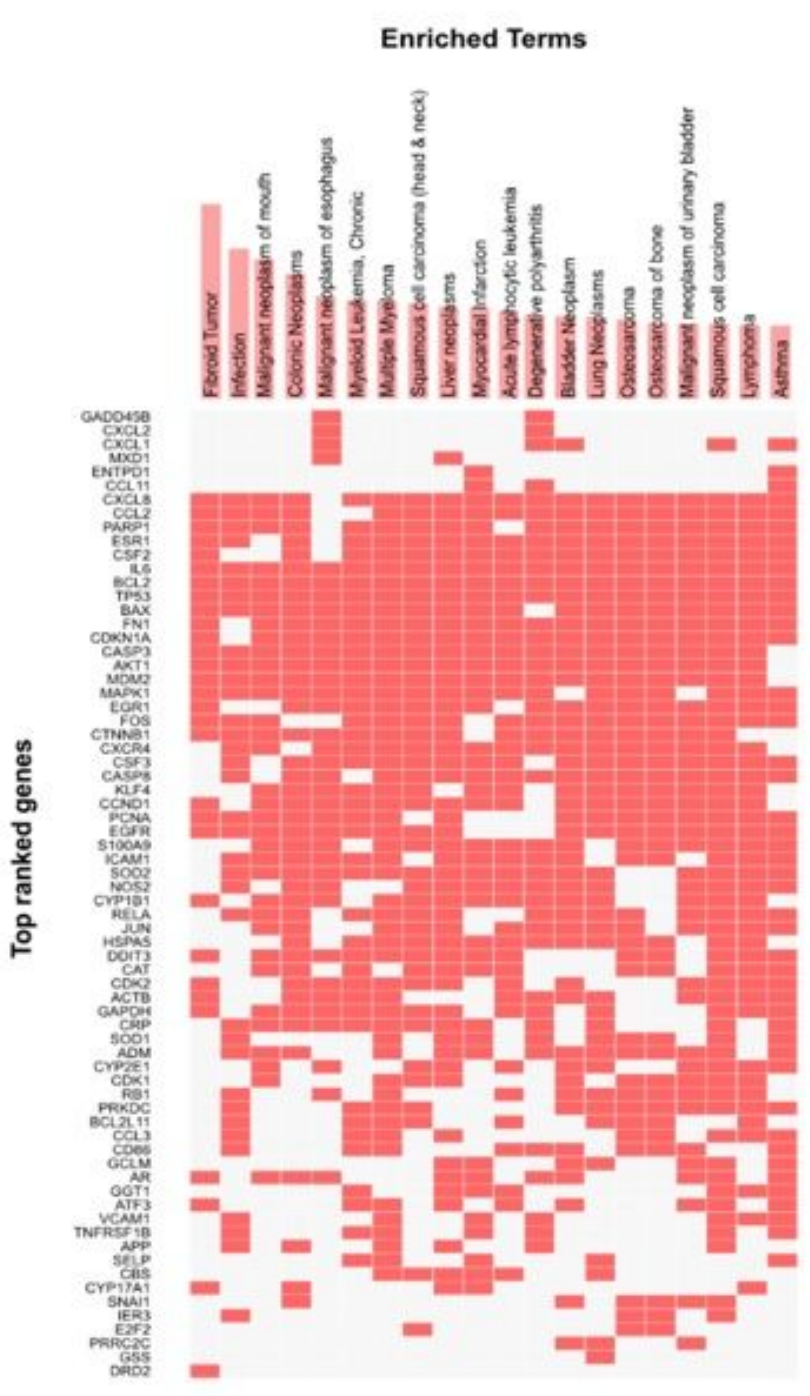

(A) DF

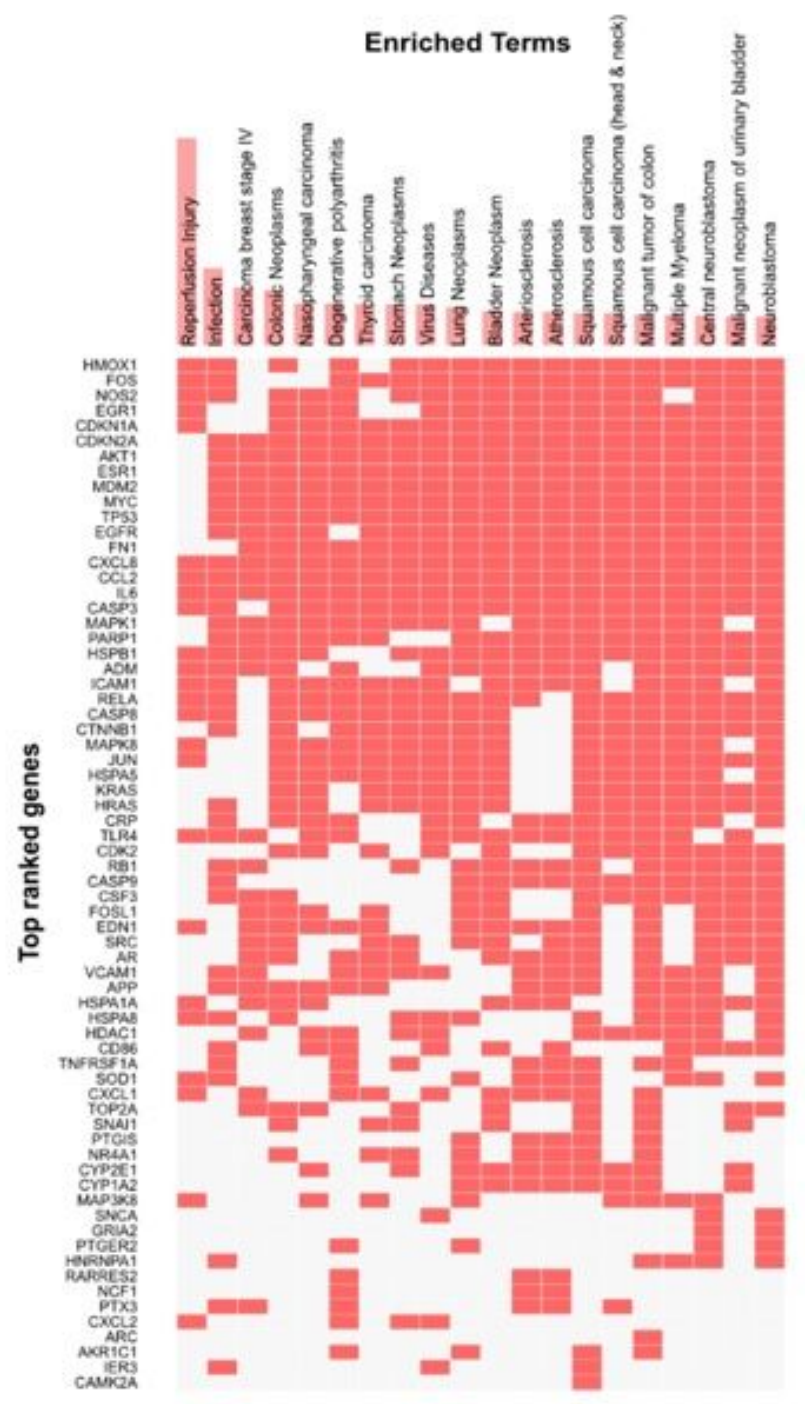

B) HFO

\section{Figure 7}

Enriched disease terms for top ranked genes in (A) DF and (B) HFO aerosol network. The gene-disease interaction matrices are created using the Enrichr tool. Rows are top ranked genes in DF and HFO network, while columns are enriched disease terms arranged based on the combined score which is a combination of $p$-value and z-score to rank enriched disease terms. The length of the colored bar with disease name represents the significance of disease terms with respect to the associated genes. The colored cells in the matrix indicates that the corresponding gene-disease association.

\section{Supplementary Files}


This is a list of supplementary files associated with this preprint. Click to download.

- AdditionalFile1.docx

- Additionalfile2.xlsx

- Additionalfile3.xlsx

- Table1.docx

- Table2.docx 